\title{
Reaproveitamento de Resíduos de Laminados de Fibra de Vidro na Confecção de Placas Reforçadas de Resina Poliéster.
}

\author{
Patrícia Risson, G. A. Carvalho, S. L. Vieira, Mara Zeni e Ademir J . Zattera
}

\begin{abstract}
Resumo: Visando o aproveitamento de resíduos de laminados de poliéster insaturado com fibra de vidro, foi realizado o estudo da incorporação do resíduo moído em placas confeccionadas à base de resina poliéster insaturado pelo processo de moldagem por compressão de preformas (BMC). Foram testadas cinco formulações com diferentes quantidades de resina poliéster, resíduo moído, aditivos e cargas. As placas foram confeccionadas em prensa hidráulica com molde plano e pressões da ordem de $18,1 \mathrm{MPa}$ à temperatura de $115^{\circ} \mathrm{C}$. Os corpos de prova, preparados segundo normas ASTM, foram submetidos a ensaios de tração, impacto Charpy e dureza do material. Os resultados dos ensaios mecânicos indicam que a substituição de fibra de vidro pelo resíduo moído no compósito polimérico promove perda de resistência à flexão, ao impacto Charpy e a dureza do compósito; a resistência à tração mostra que a incorporação do resíduo pode ter um aumento de $23 \%$ quando a quantidade de resíduo adicionada é de $20 \%$ p/p.
\end{abstract}

Palavas-chave: Resíduos, laminados de poliéster insaturado, reaproveitamento, reciclagem, fibra de vidro.

\section{Introdução}

Os materiais poliméricos sintéticos são utilizados para a produção de uma variada gama de artigos, suprindo os mais diversos requisitos funcionais de forma econômica e eficaz. Após a segunda guerra mundial intensificou-se a criação e a utilização de novos tipos de polímeros, surgindo, de maneira lenta e gradual, o uso de termofixos e fibras de vidro como reforço de peças moldadas em resina poliéster insaturado, resultando num compósito.

Os compósitos são uma classe dos materiais de engenharia em que um dos componentes (fase descontínua) confere resistência ao compósito quan- do submetido a algum tipo de esforço, enquanto que o outro componente (fase contínua) é responsável pela transferência deste esforço (componente matricial). O compósito polímero reforçado com fibra de vidro é usualmente denominado de "fiberglass" e possui as seguintes características: leveza; facilidade de transporte; rapidez de instalação; custo inferior ao de equipamentos construídos com ligas especiais; aço inoxidável ou até mesmo materiais menos nobres; propriedades mecânicas satisfatórias para aplicações estruturais, resistência química a diversos ambientes agressivos; dispensa pintura, revestimento ou qualquer proteção anticorrosiva; manutenção simples e barata; pode 
ser translúcido ou opaco, na cor desejada; possibilidade de uso em materiais que estarão em contato com alimentos; pode ser construído com detalhes complexos, sem emendas podendo ser modificado no campo com ferramentas simples ${ }^{[1]}$.

São vários os processos de fabricação de compósitos resina poliéster insaturado e fibra de vidro passíveis de desenvolvimento. Todos partem do princípio básico de processamento no qual a resina termofixa é dissolvida num solvente apropriado que faz a impregnação das fibras de reforço. A cura é realizada tanto à temperatura ambiente como em prensas ou moldes pré-aquecidos (dependendo do processo de fabricação: BMC, SMC), sendo que o tempo de cura deste último pode variar com a espessura e com o tipo de material, utilizando temperatura e pressões adequadas ${ }^{[2]}$. Figueiredo apresentou um estudo bastante completo sobre a reciclagem de termofixos à base de resina poliéster insaturado e fibra de vidro obtidos pelos processos BMC e $\operatorname{SMC}^{[3]}$.

A crescente utilização de termofixos reforçados com fibra de vidro no setor automobilístico, trouxe consigo a preocupação com a produção de resíduos sólidos no seu processamento ${ }^{[4,5]}$. Na região de Caxias do Sul (RS), são geradas cerca de 80 toneladas por mês de resíduos de resina poliéster insaturado reforçada com fibra de vidro sem utilização que comumente são lançadas em aterros ${ }^{[6]}$.

A estabilidade química, física e térmica dos compostos termorrígidos são um desafio para seu reaproveitamento, pois, ao contrário dos termoplásticos e metais, não podem ser refundidos ${ }^{[3,7]}$. Muitas técnicas têm sido apresentadas como forma de reutilizar ou degradar estes materiais, sendo que algumas têm sido criadas apenas para a utilização da porção orgânica que representa somente 20 a $25 \%$ do conteú$\mathrm{do}^{[8]}$. Dentre elas estão a incineração, a pirólise, a degradação química e a moagem e reutilização do material polimérico ${ }^{[9]}$.

Neste trabalho é avaliada a possibilidade de reutilização de resíduos sólidos gerados no processo de laminação à pistola (spray-up) como cargas reforçantes em compósitos termofixos fabricados por BMC. O processo utilizado foi o de moagem em virtude de sua facilidade de implementação e do fator econômico ${ }^{[10]}$. Estudos preliminares mostraram que o custo da moagem somado ao custo do refugo, proporcionado pelo processo, correspondem a $10 \%$ do valor da resina virgem ${ }^{[11]}$.
Tabela 1. Porcentagem de cada componente na formulação do BMC (p/p)

\begin{tabular}{lccccc}
\hline \multicolumn{1}{c}{ Amostra } & I & II & III & IV & V \\
\hline resina & 25,08 & 30,63 & 35,44 & 35,44 & 35,19 \\
aditivos & 0,97 & 0,19 & 0,17 & 0,17 & 0,83 \\
carga mineral & 8,05 & 8,33 & 7,79 & 7,79 & 7,79 \\
fibra de vidro & 49,64 & 22,92 & - & - & - \\
outros* & 16,26 & 15,02 & 13,97 & 4,97 & - \\
resíduos & 0,00 & 22,92 & 42,63 & 51,63 & 56,19 \\
\hline
\end{tabular}

*agentes tixotrópicos, de compatibilização e desmoldantes ${ }^{1,3}$

\section{Parte Experimental}

O material utilizado (resíduo de laminados de resina poliéster insaturado reforçada com fibra de vidro) era proveniente do processo de laminação à pistola e do setor de corte das rebarbas. O resíduo foi moído e analisada sua granulometria. Escolheu-se a faixa de diâmetros maior que 6 e menor que $14 \mathrm{~mm}$ (economicamente mais viável), e uma composição média de $68 \%$ de fibra de vidro e $32 \%$ de matéria orgânica (p/p).

Com a finalidade de reutilizar resíduos de laminados poliéster insaturado com fibra de vidro no processamento BMC, foram feitas cinco misturas com diferentes composições desses resíduos, conforme a Tabela 1. Depois de prontas, as misturas foram acondicionadas em um filme de polietileno e conservadas à temperatura de $25^{\circ} \mathrm{C}$, durante 10 dias. As massas de cada amostra foram então prensadas em uma prensa hidráulica com molde de chapa plana (previamente aquecido) para a confecção de placas. A pressão utilizada foi de aproximadamente $1,87 \mathrm{kgf} / \mathrm{cm}^{2}(18,1$ MPa) e a temperatura média de $115^{\circ} \mathrm{C}$.

Depois de prontas as placas, foi determinada a massa específica de cada amostra através do deslocamento do volume de água em uma proveta. A seguir, os corpos de prova foram submetidos a ensaios de tração (ASTM D-638), impacto (ASTM D-256), flexão (ASTM D-790) e dureza Barcol (ASTM D2583). Para cada medida foram utilizados três corpos de prova, de cada amostra.

\section{Resultados e Discussão}

Na tabela 2 são apresentados os resultados dos ensaios mecânicos realizados e a massa específica de cada uma das amostras feitas pelo processamento BMC. 
Tabela 2. Resultados dos testes realizados para cada formulação do BMC

\begin{tabular}{cccccc}
\hline Amostra & $\begin{array}{c}\text { Resistência à } \\
\text { tração (MPa) }\end{array}$ & $\begin{array}{c}\text { Resistência à } \\
\text { flexão (MPa) }\end{array}$ & $\begin{array}{c}\text { Dureza Barcol } \\
(\text { Barcol) }\end{array}$ & $\begin{array}{c}\text { Resistência ao } \\
\text { impacto Charpy } \\
\left(\mathbf{J} / \mathbf{c m}^{2}\right)\end{array}$ & $\begin{array}{c}\text { Massa Específica } \\
\left(\mathbf{g} / \mathbf{c m}^{3}\right)\end{array}$ \\
\hline I & 22,20 & 58,59 & 53,5 & 1,20 & 1,83 \\
II & 27,73 & 29,85 & 52,0 & 0,80 & 1,57 \\
III & 27,35 & 32,71 & 47,0 & 0,78 & 1,43 \\
IV & 22,37 & 32,71 & 43,4 & 0,31 & 1,39 \\
V & 21,70 & 30,44 & 39,5 & 0,21 & 1,27 \\
\hline
\end{tabular}

Os resultados obtidos por meio dos ensaios de tração mostraram que a incorporação do resíduo juntamente com o aumento da quantidade de resina (amostras I e II), conferiram ao compósito uma maior resistência à tração $(24,9 \%)$. Neste caso, o resíduo de laminado de fibra de vidro atua como reforço, melhorando esta pro-

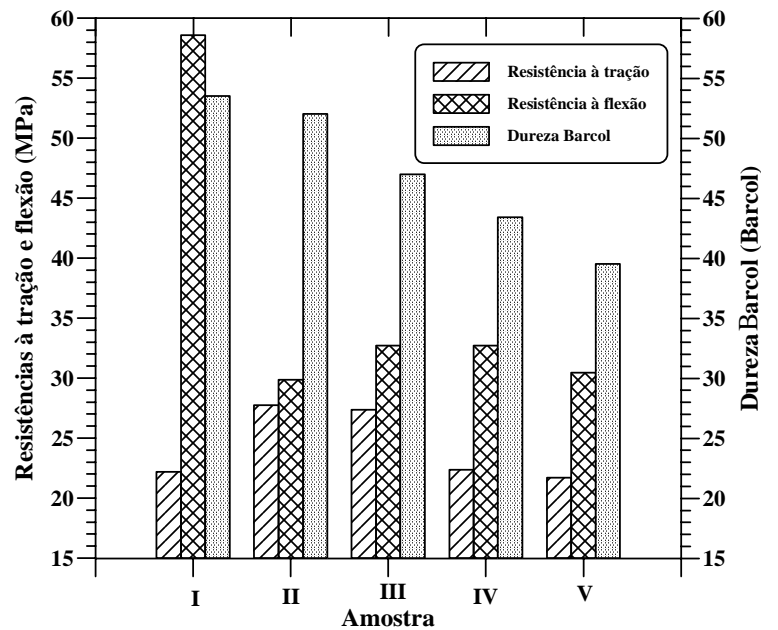

Figura 1. Resistência à tração, resistência à flexão e dureza Barcol para os compósitos estudados.

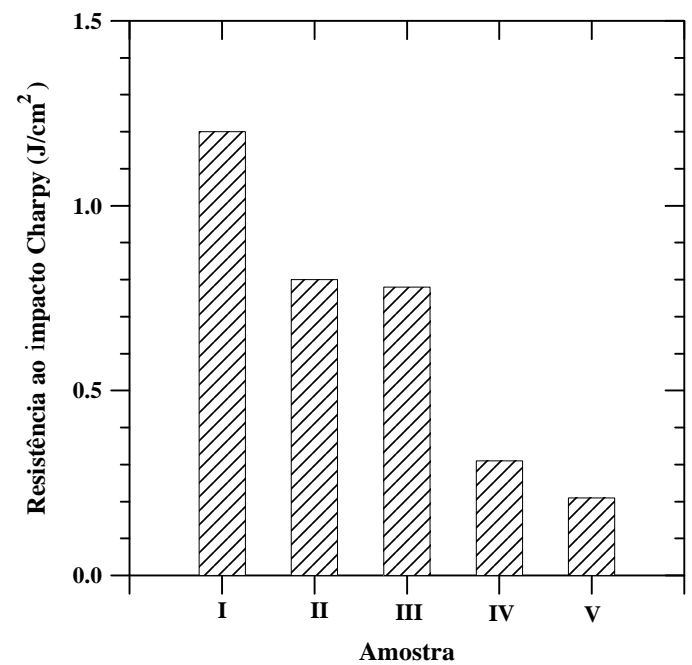

Figura 2. Resistência ao impacto Charpy para os compósitos estudados. priedade mecânica. Entretanto, aumentando-se ainda mais a concentração de resíduos e de resina sem adicionar fibra de vidro à mistura (amostra III), pouco altera a resistência à tração. Porém, se uma maior quantidade de resíduo for acrescentada (amostras IV e V), a mistura se torna menos resistente à tração.

Com relação aos ensaios de flexão, os resultados mostraram que a substituição da fibra de vidro pelo resíduo (amostras I e II) reduziu a resistência à flexão em 49\%. Para os compósitos que não continham fibra de vidro (amostras II, IV e V), o aumento da quantidade de resíduo diminui a resistência à flexão das amostras.

Nos ensaios de dureza Barcol, observou-se que, da amostra I para a II, a dureza teve redução de menos de $3 \%$. Porém, a ausência da fibra de vidro nas amostras e o aumento da concentração de resíduos (amostras III. IV e V) provocou uma diminuição de mais de $12 \%$ na dureza.

$\mathrm{Na}$ figura 1 são apresentados os resultados dos ensaios de tração, flexão e dureza Barcol para cada amostra ensaiada.

Quanto à resistência ao impacto Charpy, todas as amostras que continham uma certa quantidade de resíduo de laminado de fibra de vidro apresentaram uma diminuição desta propriedade mecânica. A figura 2 ilustra o comportamento dos diferentes compósitos com respeito à resistência ao impacto Charpy.

\section{Conclusões}

A proposta de misturar resina poliéster com resíduos de laminados de resina poliéster insaturado reforçada com fibra de vidro propiciou a obtenção de placas de excelente aspecto e com boas propriedades mecânicas, permitindo sua utilização em painéis, pisos, divisórias entre outras. 
Os resultados deste trabalho resumem-se em:

1. a substituição da fibra de vidro pelo resíduo diminui a resistência à flexão, a resistência ao impacto Charpy e a dureza do material;

2. dependendo da quantidade de resíduo adicionado, a resistência à tração pode ter um aumento da ordem de $23 \%$;

\section{Agradecimentos}

Os autores agradecem ao $\mathrm{CNPq}$, à UCS, à FAPERGS e à empresa São Marcos Fibras Ltda.

\section{Referências Bibliográficas}

1. Biryukovich, K.L. - "Glassfibre Reinforced Cement”, Budivelnik, Kiev (1994)

2. Carvalho, A. - "Manual Técnico da Fiberglass do Brasil", São Paulo (1991)

3. Figueiredo, E.M. - "Reciclagem de Plásticos Termofixos à Base de Resina Poliéster Reforçados com Fibra de Vidro", I Congresso Brasileiro de Polímeros, 460-464 (1991)

4. Anom - "El Reciclado como Fuente Rentable de Materias Primas", Revista de Plásticos Modernos, 27(327), 386-390, Madrid (1976)

5. Ferraro Jr., D. - "Reciclagem Transforma Problema em Solução", Plástico Moderno, 21(208), 20-23, São Paulo (1990)

6. CSD-GEOLOCK - Geologia e Engenharia Ambiental Ltda.; "Inventário de Resíduos Industriais e Hospitalares", Caxias do Sul, RS, p.15 (1992)
7. Bilwastsch, D. - "Garantia de Calidad en los Plásticos Reciclados", Plásticos Universalles (16), 70-74, Barcelona (1992)

8. Rubin, I.I. - "Handbook of Plastics Materials and Technology", John Wiley \& Sons, 799-1039, New York (1990)

9. Bonelli, C.M.C. - "Recuperação Secundária de Plásticos Provenientes de Resíduos Sólidos Urbanos do Rio de Janeiro", tese de mestrado IMA/UFRJ, Rio de Janeiro, julho (1993)

10. Almeida, M.G., Zeni, M. e Zattera, A.J. - "Estudo sobre o Reaproveitamento do EVA (Etileno Acetato de Vinila)", anais do XI CBECIMAT, Águas de São Pedro, dezembro (1994)

11. Zattera, A.J., Cormelato, E., Bianchi, F., De Bortoli, V. e Zeni, M. - "Reciclagem de Materiais Poliméricos" anais do II Congresso Brasileiro de Polímeros, São Paulo, 718-722, outubro (1993)

12. Maczko, J. - "An Alternative to Landfills for Mixed Plastic Waste", Plastics Engineering, 46(4), 5153, Roselle (1990).

13. Majumdar, A.J. and Ryder, J.F. - "Glassfibre Reinforcement for Cement Products", Glass Technology, 9, 78-84 (1986).

14. Majumdar, A.J. - "Glassfibre Reinforced Cement and Gypsum Products", Proc. Roy. Soc. Lond. A., (319), 69-78 (1970).

Recebido: 09/02/98 Aprovado: 30/07/98 